\title{
The analysis of overloaded trucks in indonesia based on weigh in motion data (east of sumatera national road case study)
}

\author{
Jongga Jihanny ${ }^{1, *}$, Bambang Sugeng Subagio ${ }^{1}$ and Eri Susanto Hariyadi ${ }^{1}$ \\ ${ }^{1}$ Department of Civil Engineering, Institut Teknologi Bandung, Jl. Ganesha No. 10, Bandung, 40132, Indonesia
}

\begin{abstract}
Overloaded trucks phenomena generally common in developing countries where the traffic control is poor. In Indonesia, the percentage of overloaded trucks can reach more than $60 \%$ in the total number of trucks and may be one of the substantial factors that reduce the service life of the road pavements. This paper presents the analysis results of the weigh in motion survey data at East of Sumatera National Road (Jalintim) in Indonesia and the impact of overloaded trucks on the pavement. For the analysis the simplified approach was used, the axle loads were converted into representative single-axle loads based on 4th power formula by AASHTO 1993 equation. The vehicle damage factor of vehicles is presented and will be compared with the Highways National Standard to estimate the remaining service life of pavement and IRI value prediction. The analysis showed that the vehicle damage factor that determined from weigh in motion data is extremely greater than vehicle damage factor of the national standard in Indonesia which may lead to accelerated deterioration, reducing the service life of the pavement structures and significantly influence the IRI value.
\end{abstract}

\section{Introduction}

The East of Sumatera National Road or known as Jalan Lintas Timur Sumatera/Jalintim is one of the strategic national roads in Indonesia. This road stretch from north to south of Sumatera Island and connects 6 provinces from a total of 8 provinces in Sumatera. This national road is part of the overall Asian Road Network route. Figure 1 shows the maps of Jalintim national road.

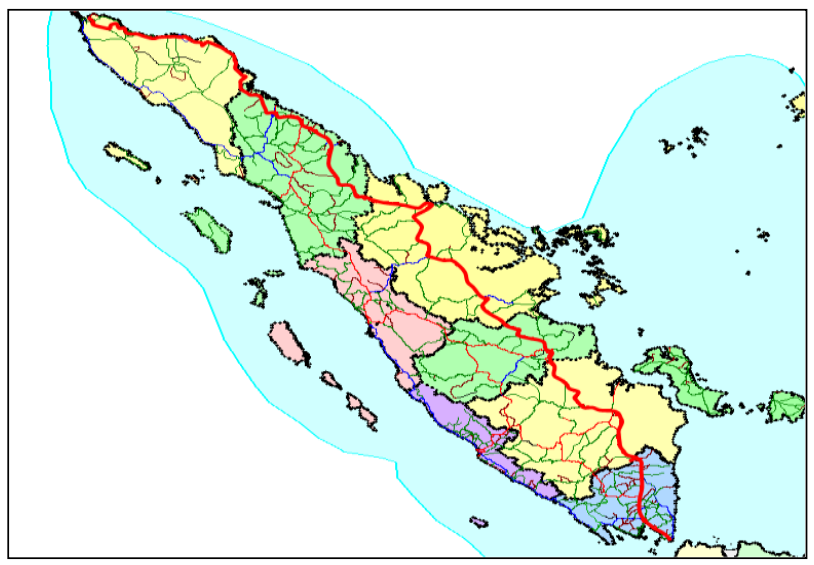

Fig. 1. Jalintim national road in Sumatera Island.

As one of strategic national road in Indonesia, Jalintim plays an important role so it needs to be maintained properly. The problem is the condition of Jalintim Road nearly always in poor condition. The pavement structure deteriorates rapidly compared their design life causing the preservation cost increased.

Main reasons that caused this problem is overloaded vehicles. A study by INDII (The Indonesia Infrastructure Initiative) stated that overloading is the main factor (nearly 50\%) that contributed to pavement failure [1]. This overloaded vehicles phenomena became common problems in developing countries [2]. This phenomena contributes a significance impact on pavement performance. As stated in the previous study of overloaded vehicles and their damage on pavement, show that they have a significant role on reducing the service life of pavement structures $[3,4]$.

The overloaded vehicle normally dominates by truck. An overloaded truck has a load or gross weight exceed their maximum legal loads. In Indonesia, main factor behind the overloaded trucks is economic issues, for example, the owner of commodities or truck owner attempt to minimize transportation cost by carrying an overload. On the other hand, law enforcement has not been optimal yet. Overload truck restrictions through weigh station failed to prevent it. Without further intervention by the government, the continuous use of overloaded trucks causes a serious problem on pavement preservation and planning policy in Indonesia.

Some of previous study in Indonesia related to overloaded trucks focus on the vehicle damage factor and remaining service life analysis $[5,6)$. While the other studies analyze the loss cost due to overloaded trucks $[7,8]$. These studies based on weigh station data and the total gross weight of the vehicle. This paper further involves the axle load analysis based on weigh in motion

\footnotetext{
${ }^{*}$ Corresponding author: jongga jihanny@itb.ac.id
} 
survey. By using these analysis, the traffic data can represent the actual load and can present a better result comparing the previous study.

Weigh-in-Motion survey (WIM) is a survey that can be used for pavement and bridge engineering, traffic data collection, traffic controls and etc [9]. Slightly different with weigh static station or other weight survey methods, WIM data has a higher accuracy data and have no interruption to traffic flows [10].

In Indonesia, since WIM survey is very limited and costly, it is usually conducted annually by Directorate General of Highway (DGH), Ministry of Public Works and Housing at several strategic national roads. The duration of survey for each location normally between several days into weeks. Although the WIM survey quite often conducted, the data has not been studied properly in Indonesia. The database of axle load and VDF value analysis has not been used well yet related to pavement design and planning policy in Indonesia. Further analysis needed to improve and update the information for the purpose of pavement design.

One of pavement condition indicator that used as a parameter in pavement management system in Indonesia is International Roughness Index (IRI). As an International standard, IRI is practically used in pavement management system. Traffic conditions, especially ESAL, have the highest significance in contributing to the IRI value because of ESAL numbers greatly affect the changes in the surface conditions of flexible pavements [11]. Thus, the prediction of IRI value demanding an appropriate design of traffic.

The objective of this present study are to analyze the traffic condition in East of National Road of Sumatera, Indonesia and to analyze the impact of overloaded truck on pavement structure. This paper present the impact of overloaded trucks on pavement structure by considering the service life and IRI value based on WIM survey

\section{Data and methods}

This section discussed about data, methods and analysis that used to reach the objectives of study.

\subsection{Weigh in motion data}

In this study, the data from 2 segments of Jalintim Road were collected since 2007 till 2014. The location is part of south segment of Jalintim Road. These 2 segment considered as the most congested than other segment since these segment heading to main port in Sumatera Island that connect to Java Island, the main island in Indonesia

the data have already been verified and filtered to remove invalid data records. Nearly more than 80,000 total number of truck that recorded in these 2 location. The detail of survey location presented in figure 2 .

Figure 3 present an information about type of truck, class and VDF standard that evaluated. The truck information was adopted from National truck configuration by Directorate General of Highway (DGH). There are 5 types of trucks that considered in the analysis of this study. This VDF standard will be compared with the VDF value that generated from WIM data survey.
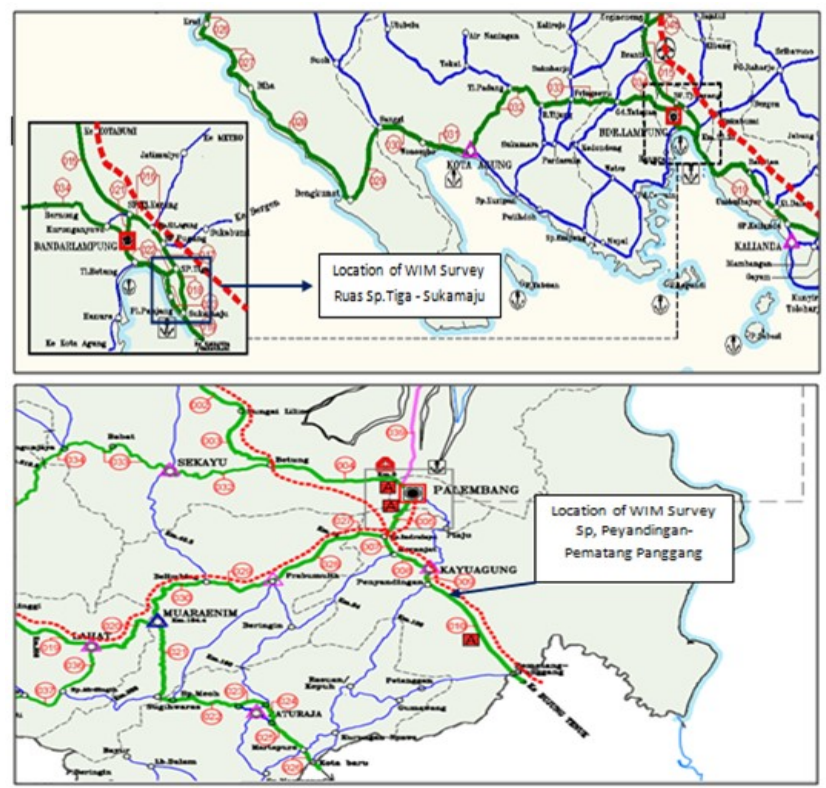

Fig. 2. Survey Location

Table 1 is a resume data of WIM survey report. Truck type of 2 axis or type 6A is the most type of truck that recorded in these WIM survey report, followed by truck type of 3 axis or type 7A.

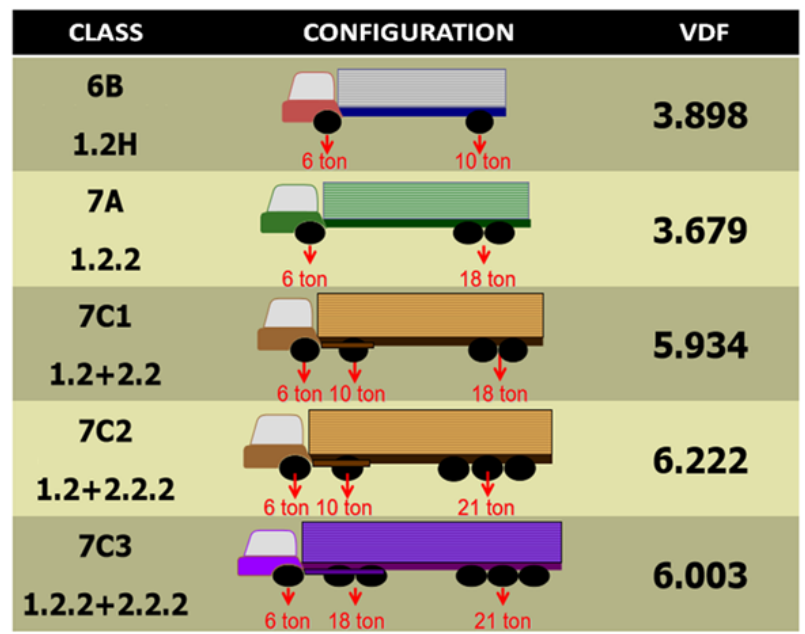

Fig. 3. Vehicle configuration

\subsection{Overloaded trucks}

The percentages of overloaded truck is estimated by identifying truck axle load that greater thanthe maximum legal limit (10 tons). Each of type truck has a different percentage number of overloaded. In figure 4, the percentage of the overloaded trucks varies for each type of truck, year of survey and location. The values is varies between $30 \%-98 \%$. 
Table 1. Resume of data

\begin{tabular}{|c|c|c|c|c|c|c|c|c|}
\hline \multicolumn{2}{|c|}{ Survey Location } & \multirow[b]{2}{*}{ Time of survey } & \multicolumn{6}{|c|}{ Data Records (type vehicle and total truck) } \\
\hline Road Segment & Province & & $6 \mathrm{~B}$ & $7 \mathrm{~A}$ & $7 \mathrm{C} 1$ & $7 \mathrm{C} 2$ & $7 \mathrm{C} 3$ & $\begin{array}{l}\text { Total } \\
\text { trucks }\end{array}$ \\
\hline $\begin{array}{lll}\text { Sp. Peyandingan } & - \\
\text { Pematang Panggang } & \\
\end{array}$ & $\begin{array}{l}\text { South } \\
\text { Sumatera }\end{array}$ & $\begin{array}{ll}2007, & 2012, \\
2013 & \end{array}$ & 35171 & 5946 & 323 & 44 & 203 & 41,687 \\
\hline Sp. Tiga - Sukamaju & Lampung & $\begin{array}{l}2007, \quad 2010, \\
2013,2014\end{array}$ & 29330 & 8912 & 211 & 220 & 525 & 39,198 \\
\hline
\end{tabular}

The result show that the majority of truck is overloaded and the traffic control in that area is very poor. Compared to other countries, this number is extremely high. Other study in Poland, the percentage of overloaded vehicles vary between $6 \%$ to $16.5 \%$ which is quite low when compared to this results [12].

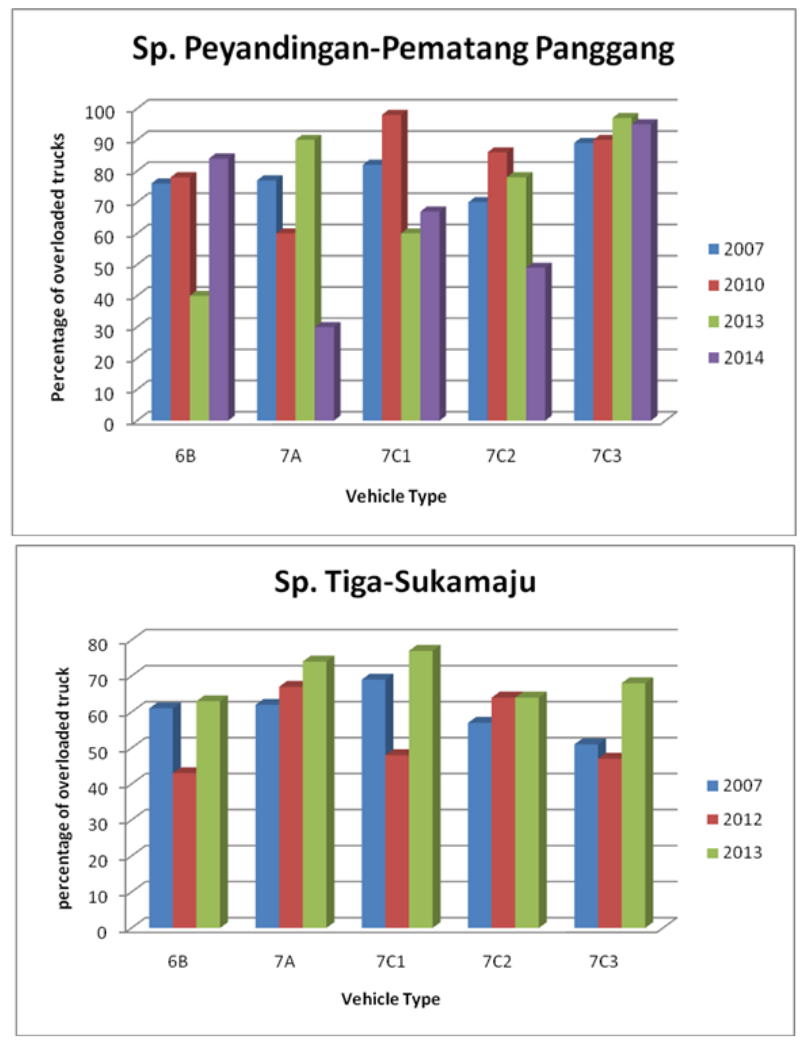

Fig. 4. The percentage of overload truck

Vehicle Damage Factor used as representation of the trucks that encountered on the pavement structure that defined as equivalent number of standard axles per truck. The VDF estimated by using the empirical approach through the 4th power formulas derived by Liddle [13]

$$
D F=k\left(Q_{j} / Q_{s}\right)^{4}
$$

DF : Damage Factor

$\mathrm{Q}_{\mathrm{j}} \quad$ : Actual Load

$\mathrm{Q}_{\mathrm{s}}$ : standard single axle load $80 \mathrm{kN}$

$\mathrm{k}: 1$ for single,

0.086 for tandem and

0.053 for tridem axle load
In this study, the vehicle damage factor was estimated from WIM survey. Since the WIM survey was conducted in 2 segment and in different years, VDF value estimated by analyzing for each year and location of survey. This was done to analyze the traffic condition and the tendency of overloaded truck.

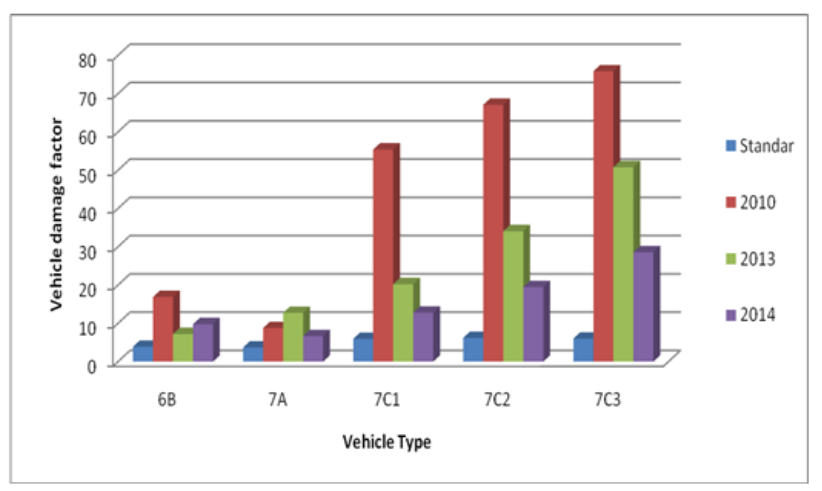

Fig. 5. VDF value at Sp. Tiga-Sukamaju

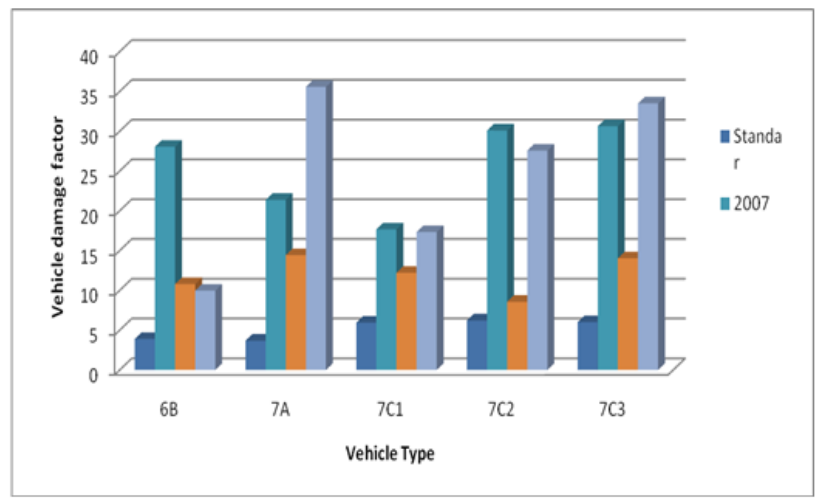

Fig. 6. VDF value at Sp. Peyandingan-Pematang Panggang

Figure 5-6 present the calculation of VDF value. The result show that the VDF value have a tendency to decreased especially in 6B truck although in other types of trucks the VDF values is ups and down.

Further analysis done by using the VDF value of truck type $6 \mathrm{~B}$ to check the tendency of the overloaded truck. Truck type 6B chosen since this kind of truck is the majority in the daily traffic data. The result can be seen in table 2. The tabel show about a mapping from VDF value comparison between overloaded VDF and standard VDF. The percentage describe the total number of $6 \mathrm{~B}$ truck that have a VDF value more than VDF standards. The overage number of VDF divided into several grup to descibe the magnitude of the overage compare to Standard VDF. 
Table 2. VDF value of truck type 6B

\begin{tabular}{|c|c|c|c|c|c|c|c|c|c|c|c|c|}
\hline \multirow{2}{*}{ Year } & \multicolumn{10}{|c|}{ Percentage of Overloaded VDF (\%) } & $\begin{array}{c}\text { Total of } \\
\text { Overloaded } \\
\text { Truck }\end{array}$ \\
\hline & $0-10$ & $10-20$ & $20-30$ & $30-40$ & $40-50$ & $50-60$ & $60-0$ & $70-80$ & $80-90$ & $90-100$ & $>100$ & 2302 \\
\hline 2007 & 15.99 & 18.07 & 18.38 & 18.55 & 11.34 & 8.60 & 5.21 & 2.00 & 1.35 & 0.52 & 0.52 & 2 \\
\hline 2010 & 13.37 & 15.84 & 15.35 & 12.11 & 13.32 & 10.31 & 7.85 & 5.91 & 4.21 & 1.74 & 18.93 & 2065 \\
\hline 2013 & 13.04 & 10.88 & 3.99 & 4.40 & 12.12 & 23.89 & 21.75 & 8.44 & 1.16 & 0.31 & 0.15 & 9040 \\
\hline 2014 & 26.13 & 23.12 & 21.11 & 17.09 & 8.04 & 4.52 & & & & & & 199 \\
\hline
\end{tabular}

From table 2, we can conclude that the overage of overloaded VDF can reach about more than 190\% compare to standard VDF especially in the earlier time survey. Then in latter time of survey there is a tendency a decresing overage value of overloaded VDF. Not only in the percentage number, but also in the range of the overage. The overage of overloaded VDF simply reach below $60 \%$ compare to VDF standards.

The VDF result (overloaded VDF) then compared with the national standard VDF for each truck that stated in figure 3. From the analysis the VDF result was extremely greater than standards vehicle damage factor. The range comparison between overloaded VDF and standard VDF about 1.38 to 12.63 times. This is the reason why the pavement structures in the location tend to rapidly deteriorates during its service life.

\subsection{Cumulative Single Axle Loads}

AASHTHO (1993) gives formula to estimates the total number of traffic during the service life by using the following Cumulative Equivalent Single-Axle Loads (CESAL) formula:

$W_{18}=\sum_{j=1}^{n} N_{j} \times V D F_{j} \times D_{D} \times D_{L} \times 365$

W18 is design traffic in design life of pavement, $\mathrm{N}_{\mathrm{j}}$ denotes number of vehicles while DD and DL are distribution factor for direction and lanes.

To analyze the impact of overloaded truck on design life, VDF value and the percentage of overloaded truck from WIM survey analysis was used to estimate the CESAL and the number of design traffic. The daily traffic data collected from Integrated Indonesia Road Management System (IIRMS). IIRMS is road maintenance management program that developed by DGH and contain important data related to road network.

The CESAL result (Overloaded CESAL) will be compared with CESAL estimation using standard load (Standard CESAL) to calculate the impact caused by overloaded trucks. Then the reduction value of service life of pavement structures can be measured.

CESAL value comparison is to compare the Overloaded and Standard CESAL. Figure 7 is a representation of CESAL value comparison. As shown in that figure, the CESAL value from WIM data analysis is greater than the Standard CESAL value. In the end of design life (10 years), total number of standard CESAL is 35.02 million ESAL. Whilst the total number of Overloaded CESAL is 96.22 million ESAL. The
Overloaded CESAL value is nearly 2.75 times more than Standard CESAL.

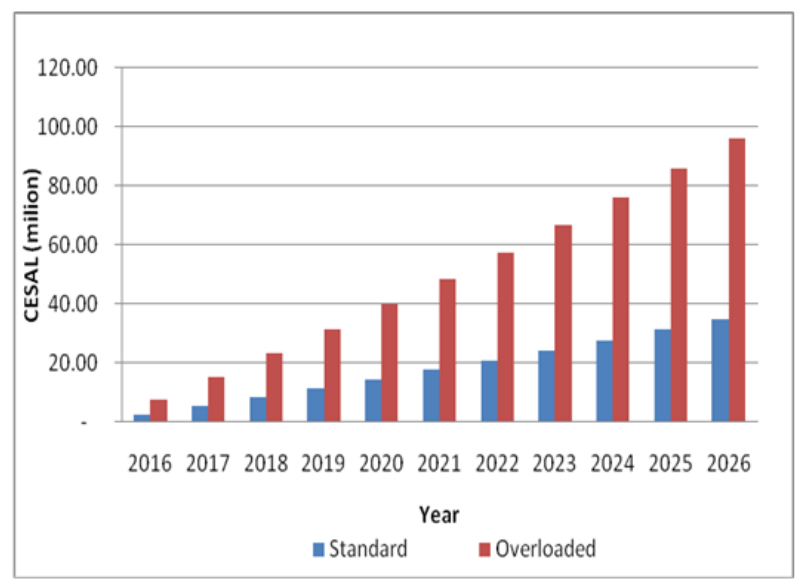

Fig. 7. CESAL comparison

\section{Overloaded truck impact on pavement structure}

\subsection{Service life}

To calculate the impact of overloaded vehicles on pavement structure, we can calculate the remaining service life of pavement. Remaining service life (RSL) has been defined as the estimation of total years that a pavement will be functionally and structurally in a normal condition by with only routine preservation [14]. The RSL was calculated using the formula:

$R S L=\frac{\text { CESAL Standard }}{\text { CESAL Overloaded }} \times D L$

Where:

RSL is remaining service of pavement (years) and DL is design life (10 years)

By using the this equation, the RSL of pavement in this study is 3.64 years. From this result, we can conclude that there is a reduction in service life approximately about 6.36 years from the design life of pavement. Which means the service life of the pavement that design in 10 years of design life, will ended in 3 years and 8 months. 


\subsection{International Roughness Index (IRI)}

The IRI is calculated from the road profile or pavement surface. This study present IRI determination based on Indonesian Integrated Road Management System (IIRMS) that adopted from simplified methods by Paterson and Attoh-Okine [15], where the formula is:

$I R I_{n}=1.04 e^{0.023 n}\left[I R I_{0}+263(1+S N C)^{-5} x C S A_{n}\right]$

where :

$\mathrm{IRI}_{\mathrm{n}}=$ roughness index at $\mathrm{n}, \mathrm{IRI}(\mathrm{m} / \mathrm{km})$

$\mathrm{IRI}_{0}=\quad$ initial roughness index, IRI $(\mathrm{m} / \mathrm{km})$

$\mathrm{SNC}=$ Modified Structure Number Capacity depend on pavement type

$\mathrm{CSA}_{\mathrm{n}}=$ CESAL at $\mathrm{n}$ (per 1 million ESAL)

Table 3. Road condition based on IRI value (DGH Standard)

\begin{tabular}{|c|c|c|}
\hline Road Condition & IRI value & $\begin{array}{c}\text { Pavement } \\
\text { Maintenance }\end{array}$ \\
\hline Good & IRI $\leq 4$ & Routine \\
\hline Medium & $4<$ IRI $\leq 8$ & Periodic \\
\hline Minor Damaged & $8<$ IRI $\leq 12$ & Rehabilitation \\
\hline Major Damaged & IRI $>12$ & Reconstruction \\
\hline
\end{tabular}

Using equation (4), IRI value can be predicted in design life of pavement both for standard condition and overloaded condition. By estimate both of these condition, the impact of overloaded truck on pavement can be measured.

From table 3, there are 4 types of pavement condition based on IRI value and types of pavement maintenance. Routine maintenance and periodic maintenance needed to maintain the pavement condition to be able serve the traffic in design life. The IRI value comparison can be seen in figure 9. This figure show a cumulative value of IRI without pavement treatment.

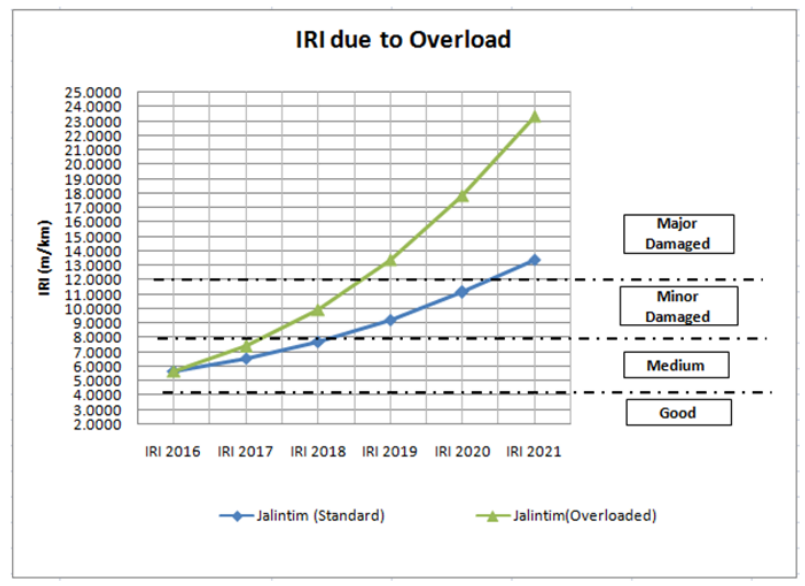

Fig. 8. IRI value comparison
By considering the pavement maintenance into IRI value comparison, the significant impact of overloaded truck can be seen in table 4 . In overloaded condition, the number of periodic maintenance needed is bigger than in standard condition. In other words, the government should prepare extra budget for maintenance and proved

Table 4. IRI comparison value and pavement maintenance

\begin{tabular}{|c|c|c|c|c|}
\hline \multirow{2}{*}{ Years } & \multicolumn{2}{|c|}{ Standard } & \multicolumn{2}{c|}{ Overloaded } \\
\cline { 2 - 5 } & CESAL & $\begin{array}{c}\text { IRI } \\
\text { Prediction }\end{array}$ & CESAL & $\begin{array}{c}\text { IRI } \\
\text { Prediction }\end{array}$ \\
\hline 2016 & 2.73 & 5.68 & 7.51 & 5.68 \\
\hline 2017 & 5.55 & 2.00 & 15.25 & 2.00 \\
\hline 2018 & 8.45 & 2.89 & 23.22 & 4.21 \\
\hline 2019 & 11.44 & 4.10 & 31.43 & 2.00 \\
\hline 2020 & 14.52 & 2.00 & 39.89 & 5.70 \\
\hline 2021 & 17.69 & 3.71 & 48.60 & 2.00 \\
\hline
\end{tabular}

Where:

$$
\text { Routine maintenance }
$$

\section{Conclusion}

This study outlines weigh in motion survey data consideration in traffic data analysis at East of Sumatera National Road (Jalintim) in Indonesia to estimate the impact of overloaded trucks on the pavement structures. Nearly more than 80,000 total number of truck that recorded and from the analysis found that the total of overloaded truck is varies between $30 \%-98 \%$ for different type of truck, time and survey location.

The specific result of this study show that the VDF values form WIM survey report is extremely greater than the standard VDF. The overloaded trucks contributed greatly in reducting the service life of pavement. On the other hand, by using IRI as pavement condition indicator, the overloaded truck proved to be costly in pavement management system's budgets.

From this study we can conclude that the overloaded truck has a severe damage to the pavement especially on service life. The percentage of overloaded truck that found in this study signifies the traffic control is poor. The government need to enforce a restriction regarding this problem.

The study is supported by ITB research program. The data were provided by Directorate General of Highway (DGH), Ministry of Public Works and Housing

\section{References}

1. Directorate General of Highway, Handling the vehicle overloading. Indonesia Transport, Supply Chain and Logistics. (2016).

2. L.G. Fuentes, L.F. Macea, A. Vergara, G.W. Flintsch, A.E. Alvarez, O.J. Reyese, Evaluation of trucks factors for pavement design in developing 
countries. Procedia of Social and Behavioral Sciences 53,1141-1150. (2012).

3. J. Mohammadi, and N. Shah, Statistical evaluation of truck overloads. J. of Trans. Eng. 118 (5), 651665. (1992)

4. J.C. Pais, S.I.R. Amorim, and M.J.C. Minhoto, Impact of traffic overload on road pavement performance. J. of Trans. Eng. 139 (9), 873-879. (2013).

5. L. Sentosa, and A.A. Roza, Analysis of the Impact of Overloading Vehicle on Design Life of Rigid Pavement Structures. Civil Eng. Journal. 19, 161168. (2012). (written in bahasa)

6. Syafriana, S.M. Saleh and R. Anggraeni, Evaluation of road service life with overloading at east of sumatera road in aceh province. Proceeding of The 18th FSTPT International Symposium. (2015). (written in bahasa)

7. A.T. Mulyono, and M. Antameng, Analysis of loss cost of road pavement distress due to overloading freight transportation. J of the EASTS. 8, 706-721. (2010).

8. S.M. Saleh, O.Z. Tamin, A. Sjafruddin, and R.B. Frazila, Reducing road maintenance cost caused of overloading trucks with multimodal freight transportation policy. Proceedings of the EASTS. 7, 159-159. (2009).

9. B. Jacob, V.F.L. Beaumelle, Improving truck safety: potential of weigh in-motion technology. IATSS Res. 34(1):9-15. (2010).

10. R.B. Machemehl, C.E. Lee, and C.M. Walton, Truck Weight Surveys by In-Motion Weighing, Research Report No. 181-1F, Center for Highway Research, Univ. of Texas. (1975)

11. A.I. Rifai, S.P. Hadiwardoyo, A.G. Correia, P.A. Pereira and P. Cortez, The Data Mining applied for the prediction of highway roughness due to overloaded trucks. Inter. J. of Tech. 6(5), 751-761. (2015).

12. D. Rys, J. Judycki And P. Jaskula, Analysis of effect of overloaded vehicles on fatigue life of flexible pavements based on weigh in motion (WIM) data. Inter. J. of Pavement Eng. 17 (8), 716726. (2016).

13. AASHTO, The AASHTO guide for design of pavement structures. AASHTO. (1993).

14. D. Gedafa, M. Hossain, R. Miller, and T. Van, Estimation of Remaining Service Life of Flexible Pavements from Surface Deflections. J. of Transp. Eng. 136 (4), 342-352. (2010).

15. W. D. Paterson and A. Busby, Simplified Models of Paved Road Deterioration Based on HDM-III. TRB, 71st Annual Meeting, Washington, D.C. (1992). 